\section{DENTAL THERAPISTS HAMPERED BY UNFAIR PRESCRIBING RIGHTS}

New president of the British Association of Therapists (BADT), Fiona Sandom, is pledging to work towards changing the 'unfair' status quo on prescribing rights for dental therapists.

It comes as physiotherapists were granted powers to prescribe (a restricted list of) medicines under new laws coming into force in Wales, Fiona's home country.

The change - also applying to chiropodists and podiatrists - is aimed at easing the pressure on these areas of the NHS.

Nurses, pharmacists and optometrists can already prescribe certain medicines, with powers now extended to additional groups of health professionals, subject to training.

Fiona explained: 'It's unfair and hampers our work greatly, since we are unable to carry out the full scope of our practice and whilst some of our places of work have Patient Group Directions (PGDs) in place, they are still extremely limiting.'

Fiona is already in negotiations with the chief dental officers in the BADT's bid towards changing prescription rights for therapists.

Fiona said that as president she wants to make a difference to the way dental therapists care for patients and increase their access to dental care. "We are aware of the discrepancy over the access to dental care, especially in rural and deprived areas. As dental therapists, we are able to help the profession deliver preventative - as well as restorative - care and with prescribing rights, we can contribute to improving the oral health in Britain while working to our full scope of practice.'

\section{A PGD is a written}

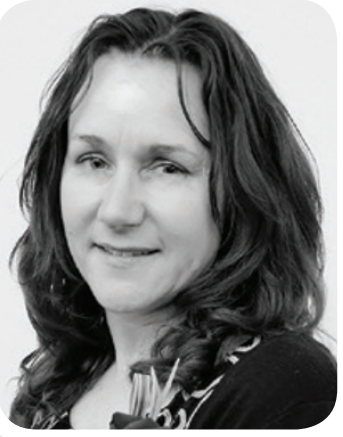

instruction allowing listed

healthcare professionals to sell, supply or administer named medicines in an identified clinical situation without the need for a written, patient-specific prescription from an approved prescriber.

The Human Medicines Regulations 2012 require that both a dentist and a pharmacist must sign a PGD. For practices providing NHS primary dental services, the PGD must also be signed on behalf of the commissioning body.

For private dental practices in England and registered with the CQC, the PGD must be signed by a dentist and a pharmacist and by or on behalf of the registered provider and, if there is a relevant manager for the practice or clinic, by that manager.

For private practices in Wales, the PGD must be signed by the private dentist who is treating the person, a pharmacist and, if there is a manager for the practice or clinic, by that manager.

An interview with Fiona Sandom, new BADT President, appears in BDJ Team this November (zmag pages 5-6).

\title{
HIGH CARIES LEVELS AMONG 3-YEAR-OLDS
}

Twelve percent of three-year-olds in England suffer from visible tooth decay, according to a survey conducted by Public Health England (PHE).

This is the first national survey of the oral health of three-year-old children in England and was carried out at nurseries, children's centres and playgroups in 2013. Over 53,000 children were examined, representing $8 \%$ of the total age three population across England.

The results show that those affected by tooth decay had an average of three decayed teeth. There was a dramatic variation in tooth decay prevalence across the county, ranging from $2 \%$ to $34 \%$. However, the large majority of children in this age group - $88 \%$ - have no decay at all. This reflects trends of significant improvements in dental health since the introduction of fluoride toothpaste in 1976. In some cases Early Childhood Caries was found: decay affecting the upper front teeth spreading rapidly to other teeth and related to the consumption of sugary drinks in baby bottles or sipping cups.

Dr Sandra White, Director of Dental Public Health at PHE, said: 'While there have been significant improvements to the nation's oral health, some areas still experience problems with tooth decay among young children. Thankfully [this] can be prevented by following a healthy lifestyle, by parents and carers reducing the amount of sugary foods and drinks they give their children and supporting them to brush their teeth twice a day with a fluoride toothpaste, especially just before bedtime'

TIPS AND ADVICE FOR PARENTS AND CARERS

Public Health England recommends

the following tips and advice for parents

and carers of young children for good

oral health:

- Reduce amount and frequency of sugary foods and drinks given to young children

- Don't add sugar to weaning foods or drinks

- Aim to introduce drinking from a freeflow cup from six months old and stop feeding from a bottle at 12 months

- Start brushing children's teeth as soon as the first tooth appears and supervise brushing until age seven or eight. Brush kids' teeth twice daily, including just before bed, using fluoride toothpaste

- From age three, use a pea-sized amount of fluoride toothpaste; for younger children a smear

- Use only sugar-free medicines.

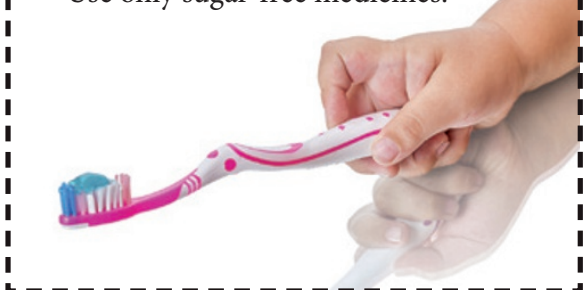

\section{GENERAL CPD ANSWERS, DENTAL EROSION, OCTOBER ISSUE}

Managing dental erosion, by Carolyn Renton, http://www.nature.com/articles/ bdjteam 2014109 .

\begin{tabular}{|l|l|}
\hline Question & Answer \\
\hline 1 & C \\
\hline 2 & B \\
\hline 3 & A \\
\hline 4 & D \\
\hline 5 & C \\
\hline 6 & B \\
\hline 7 & B \\
\hline 8 & A \\
\hline
\end{tabular}

Do you have a news story that you would like included in BDJ Team? Send your press release or a summary of your story to the Editor at bdjteam@nature.com. 